Louisiana State University

LSU Digital Commons

Faculty Publications

Department of Biological Sciences

8-15-2007

\title{
Enhanced electrogenerated chemiluminescence in the presence of fluorinated alcohols
}

\author{
David J. Vinyard \\ Missouri State University \\ Mark M. Richter \\ Missouri State University
}

Follow this and additional works at: https://digitalcommons.Isu.edu/biosci_pubs

\section{Recommended Citation}

Vinyard, D., \& Richter, M. (2007). Enhanced electrogenerated chemiluminescence in the presence of fluorinated alcohols. Analytical Chemistry, 79 (16), 6404-6409. https://doi.org/10.1021/ac071028x

This Article is brought to you for free and open access by the Department of Biological Sciences at LSU Digital Commons. It has been accepted for inclusion in Faculty Publications by an authorized administrator of LSU Digital Commons. For more information, please contact ir@lsu.edu. 


\title{
Enhanced Electrogenerated Chemiluminescence in the Presence of Fluorinated Alcohols
}

\author{
David J. Vinyard and Mark M. Richter*
}

Department of Chemistry, Missouri State University, Springfield, Missouri 65897

The electrochemistry, UV-vis absorption, photoluminescence (PL), and coreactant electrogenerated chemiluminescence (ECL) of Ru(bpy) $3^{2+}$ (where bpy $=2,2^{\prime}$-bipyridine) have been obtained in a series of hydroxylic solvents. The solvents included fluorinated and nonfluorinated alcohols and alcohol/water mixtures. Tri- $\boldsymbol{n}$-propylamine was used as the oxidative-reductive ECL coreactant. Blue shifts of up to $30 \mathrm{~nm}$ in PL emission wavelength maximums are observed compared to a $\mathrm{Ru}(\mathrm{bpy}) 3^{2+} / \mathrm{H}_{2} \mathrm{O}$ standard due to interactions of the polar excited state (i.e., ${ }^{*} \mathrm{Ru}(\mathrm{bpy}){ }_{3}{ }^{2+}$ ) with the solvent media. For example, Ru(bpy) ${ }_{3}{ }^{2+}$ in water has an emission maximum of $599 \mathrm{~nm}$ while in the more polar hexafluoropropanol and trifluoroethanol it is 562 and $571 \mathrm{~nm}$, respectively. ECL spectra are similar to PL spectra, indicating the same excited state is formed in both experiments. The difference between the electrochemically reversible oxidation $\left(\mathrm{Ru}(\mathrm{bpy}) 3_{3}{ }^{2+/ 3+}\right)$ and first reduction $\left(\mathrm{Ru}(\mathrm{bpy})_{2}{ }^{2+/ 1+}\right)$ correlates well with the energy gap observed in the luminescence experiments. Although the ECL is linear in all solvents with [Ru(bpy) ${ }^{2+}$ ] ranging from 100 to $0.1 \mathrm{~nm}$, little correlation between the polarity of the solvent and the ECL efficiency ( $\phi_{\mathrm{ecl}}=$ number of photons per redox event) was observed. However, dramatic increases in $\phi_{\mathrm{ecl}}$ ranging from 6- to 270-fold were seen in mixed alcohol/water solutions.

Photoluminescent polypyridine complexes of Ru(II) (e.g., Ru(bpy) ${ }_{3}{ }^{2+}$, where bpy $=2,2$-bipyridine), Os(II), and Re(I) have been extensively studied due to their low-lying metal-to-ligand chargetransfer (MLCT) excited states. ${ }^{1,2}$ Ruthenium complexes have received particular attention due to their relatively high emission quantum yields (e.g., $\phi_{\mathrm{em}}\left(\mathrm{H}_{2} \mathrm{O}\right)$ of $\mathrm{Ru}(\mathrm{bpy}){ }_{3}{ }^{2+} \cong 4.2 \%$ ), ${ }^{3,4}$ long excited-state lifetimes (e.g., $\tau \cong 600 \mathrm{~ns}$ ), and the sensitivity of the excited-state to environmental conditions (e.g., solvent, electrolyte, and temperature). Fundamental electrochemical, ${ }^{5}$ spectro-

* To whom correspondence should be addressed. E-mail: MarkRichter@ MissouriState.edu.

(1) Kober, E. M.; Sullivan, B. P.; Dressick, W. J.; Caspar, J. V.; Meyer, T. J. J. Am. Chem. Soc. 1980, 102, 7383.

(2) (a) Roundhill, D. M. Photochemistry, Photophysics and Photoredox Reactions of $\mathrm{Ru}(\mathrm{bpy})_{3}{ }^{2+}$ and Related Complexes. Photochemistry and Photophysics of Metal Complexes; Plenum: New York, 1994; Chapter 5. (b) Kalyanasundaram, K. Applications of Photochemistry of Polypyridyl Complexes. Photochemistry of Polypyridine and Porphyrin Complexes; Academic Press: New York, 1992; Chapter 1.

(3) Van Houten, J.; Watts, R. J. J. Am. Chem. Soc. 1976, 98, 4853.

(4) Caspar, J. V. and Meyer, T. J. J. Am. Chem. Soc. 1983, 105, 5583-5590.

(5) Tokel, N.; Bard, A. J. J. Am. Chem. Soc. 1972, 94, 2862. scopic, ${ }^{1-3}$ and electrogenerated chemiluminescence ${ }^{6-11}$ studies of $\mathrm{Ru}$ (II) systems have been crucial to arriving at an understanding of their ground-and excited-state properties such that substances having potential for specific applications can be designed at the molecular level. For example, they have found application in areas such as molecular catalysis, ${ }^{12}$ solar energy conversion, ${ }^{13}$ colorimetric analysis, ${ }^{14}$ herbicides, ${ }^{15}$ molecular recognition, ${ }^{16}$ self-assembly, ${ }^{17}$ and immunoassay and nucleic acid probes. ${ }^{18}$

Fluorinated alcohols such as 2,2,2-trifluoroethanol (TFE), 1-phenyl-2,2,2-trifluoroethanol (PhTFE) and 1,1,1,3,3,3-hexafluoro2-propanol (HFIP), Chart 1, have remarkable solvent properties that distinguish them from their nonfluorinated analogues. They denature the native structure of proteins and induce helicity in

(6) (a) Bard, A. J.; Debad, J. D.; Leland, J. K.; Sigal, G. B.; Wilbur, J. L.; Wohlstadter, J. N. Electrochemiluminescence. In Encycopedia of Analytical Chemistry; Meyers, R. A., Ed.; Wiley: Chichester, 2000. (b) Knight, A. W.; Greenway, G. M. Analyst 1994, 119, 879. (c) Gerardi, R. D.; Barnett, N. W.; Lewis, A. W. Anal. Chim. Acta 1999, 378 (1-3), 1-43. (d) Mitschke, U.; Bauerle, P. J. Mater. Chem. 2000, 10 (7), 1471-1507. (e) Aboul-Enein, H.; Stefan, R. I.; van Staden, J. F.; Zhang, X. R.; Garcia-Campana, A. M.; Baeyens, W. R. G. Crit. Rev. Anal. Chem. 2000, 30 (4), 271-289. (f) Knight, A. W. Electrogenerated Chemiluminescence. In Chemiluminescence in Analytical Chemistry; Garcia-Campaña, A. M., Baeyens, W. R. G., Eds.; Marcel Dekker: New York, 2001. (g) Andersson, A.-M.; Schmehl, R. H Sensors Based on Electrogenerated Chemiluminescence. In Optical Sensors and Switches; Ramamurthy, V., Schanze, K. S., Eds.; Molecular and Supramolecular Photochemistry 7; Marcel Dekker: New York, 2001; pp 153-187. (h) Fahnrich, K. A.; Pravda, M.; Guilbault, G. G. Talanta 2001 54 (4), 531-559. (i) Richter, M. M. Electrochemiluminescence. In Optical Biosensors: Present and Future; Ligler, F. S., Rowe-Taitt, C. A., Eds.; Elsevier: New York. 2002; pp 173-205. (j) Kulmala, S.; Suomi, J. Anal. Chim. Acta 2003, 500 (1-2), 21-69. (k) Knight, A. W. Trends Anal. Chem. 1999 , 18 (1), 47-62.

(7) Faulkner, L. R.; Bard, A. J. Techniques of Electrogenerated Chemiluminescence. In Electroanalytical Chemistry; Bard, A. J., Ed.; Marcel Dekker: New York, 1977; Vol. 10, pp 1-95.

(8) Faulkner, L. R.; Glass, R. S. Electrogenerated Chemiluminescence. In Chemical and Biological Generation of Excited States; Waldemar, A., Giuseppe, C., Eds.; Academic Press: New York, 1982; Chapter 6.

(9) (a) Bard, A. J.; Faulkner, L. R. Electrochemical Methods; Wiley: New York, 1980. (b) Bard, A. J.; Faulkner, L. R. Electrochemical Methods: Fundamentals and Applications, 2nd ed.; Wiley: New York, 2001.

(10) Electrogenerated Chemiluminescence; C. Bard, C., Ed.; Marcel Dekker: New York, 2004.

(11) Richter, M. M. Chem. Rev. 2004, 104, 3003 - 3036.

(12) (a) Keene, F. R.; Sullivan, B. P. Mechanisms of the Electrochemical Reduction of Carbon Dioxide Catalyzed by Metal Complexes. In Electrochemical and Electrocatalytic Reactions of Carbon Dioxide; Sullivan, B. P., Kirst, K., Guard, H. E., Eds.; Elsevier Press: New York, 1993. (b) Meyer, T. J.J. Electrochem. Soc. 1984, 131, 221C. (c) Beer, R. H.; Jimenez, J.; Drago, R. S. J. Org. Chem. 1993, 58, 1746.

(13) Cole-Hamilton, D. J.; Bruce, D. W. Decomposition of Water into its Elements, in Comprehensive Coordination Chemistry, The Synthesis, Reactions, Properties and Applications of Coordination Compounds. In Comprehensive Coordination Chemistry; Wilkinson, G., Gillard, R., McCleverty, J., Eds.; Pergamon Press: London, 1987: pp 487-540. 


\section{Chart 1. Structures of 2,2,2-Trifluoroethanol (TFE), 1-Phenyl-2,2,2-trifluoroethanol (PhTFE), and 1,1,1,3,3,3-Hexafluoro-2-propanol (HFP)}

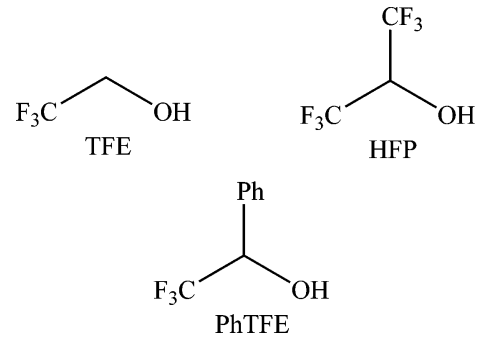

peptides ${ }^{19}$ have high ionizing power ${ }^{20}$ and acidic character ${ }^{21}$ (e.g., $\mathrm{p} K_{\mathrm{a}}=12.4$ for TFE and 9.3 for HFIP compared to 15.9 for ethanol and 17.1 for 2-propanol), are strong hydrogen bond donors ${ }^{22}$ and poor nucleophiles, ${ }^{23}$ and stabilize radical cations. ${ }^{24}$ They have also been shown to be exceptional solvents for a variety of reaction conditions, most notably oxidations. ${ }^{25}$ Fluorinated alcohols are also more polar than their nonfluorinated counterparts, and this can lead to changes in excited-state dynamics. For example, the photoluminescence (PL) emission maximum of tris(bipyridyl)ruthenium(II) $\left(\mathrm{Ru}(\mathrm{bpy}){ }_{3}{ }^{2+}\right.$ ) shifts $20 \mathrm{~nm}$ more blue in the presence of TFE compared to a pure ethanol solution..$^{26,27}$ This was attributed to the enhanced polarity and extensive hydrogen bonding in TFE. ${ }^{27}$ Therefore, it is surprising that the electrochemical and electrogenerated chemiluminescence (ECL) properties of luminophores in fluorinated alcohols have not been thoroughly investigated.

Electrogenerated chemiluminescence (also referred to as electrochemiluminescence) is a technique that involves the

(14) Schilt, A. A. Analytical Applications of 1,10-phenanthroline and Related Compounds; Pergamon Press: New York, 1969

(15) Gut, L. J.; Lee, K.; Juvik, J. A.; Rebeiz, C. C. and Rebeiz, C. A. Pestic. Biochem. Physiol. 1994, 50, 1.

(16) Ber, P. D.; Chen, Z.; Goulden, A. J.; Grieve, A.; Hesek, D.; Szemes, D.; Wear, T. J. Chem. Soc., Chem. Commun. 1994, 1269.

(17) (a) Lehn, J.-M. Angew. Chem., Int. Ed. Engl. 1988, 27, 89. (b) Lehn, J.-M. Angew. Chem., Int. Ed. Engl. 1990, 29, 1304.

(18) Long, E. C.; Barton, J. K. Acc. Chem. Res. 1990, 23, 271.

(19) (a) Andersen, N. H.; Dyer, R. B.; Fesinmeyer, R. M.; Gai, F.; Liu, Z. H.; Neidigh, J. W.; Tong, H. J. Am. Chem. Soc. 1999, 121 (42), 9879-9880. (b) Mulla, H. R.; Cammers-Goodwin, A. J. Am. Chem. Soc. 2000, 122 (4), 738-739. (c) Cammers-Goodwin, A.; Allen, T. J.; Oslick, S. L.; McClure, K. F.; Lee, J. H.; Kemp, D. S. J. Am. Chem. Soc. 1996, 118 (13), 3082-3090. (d) Hong, D. P.; Hoshino, M.; Kuboi, R.; Goro, Y.J. Am. Chem. Soc. 1999, 121 (37), 8427-8433.

(20) Reichardt, C. Chem. Rev. 1994, 94 (8), 2319-2358.

(21) Eberson, L.; Hartshorn, M. P.; Persson, O. J. Chem. Soc., Perkin Trans. 2 1995, 9, 1735-1744.

(22) Kamlet, M. J.; Abboud, J.-L. M.; Abraham, M. H.; Taft, R. W. J. Org. Chem. 1983, 48, 2877.

(23) a) Allard, B.; Casadevall, A.; Casadevall, E.; Largeau, C. Nouv. J. Chim. 1979, 3 (5), 335-341. (b) Allard, B.; Casadevall, A.; Casadevall, E.; Largeau, C. Nouv. J. Chim. 1980, 4 (8-9), 539 - 545. (c) Schadt, F. L.; Bentley, T. W.; Schleyer, P. V. R. J. Am. Chem. Soc. 1976, 98 (24), 7667-7675. (d) Leonard, N. J.; Neelima, A. Tetrahedron Lett. 1995, 36 (43), 7833-7836.

(24) See, for example: (a) Eberson, L.; Hartshorn, M. P.; Persson, O.; Radner, F. Chem. Commun. 1996, 18, 2105-2111. (b) Kita, Y.; Egi, M.; Takada, T.; Tohma, H. Synthesis 1999, 5, 885-897.

(25) Begue, J.-P.; Bonnet-Delphon, D.; Crousse, B. Selective and Clean Reactions in Fluorinated Alcohols. In Handbook of Fluorous Chemistry; Gladysz, J. A., Curran, D. P., Horvath. I. T., Eds.; Wiley-VCH: Weinheim, 2005; pp 341350.

(26) Hartmann, P.; Leiner, M. J. P.; Lippitsch, M. E. J. Fluoresc. 1995, 5, 179182.

(27) Hartmann, P.; Leiner, M. J. P.; Draxler, S.; Lippitsch, M. E. Chem. Phys. 1996, 207, 137-146. formation of excited states at or near the surface of an electrode and is a sensitive probe of electron- and energy-transfer processes at electrified interfaces. ${ }^{6-11} \mathrm{ECL}$ is also being commercially developed for use in clinical analyses (e.g., immunnoassays, DNA probes) using $\mathrm{Ru}(\mathrm{bpy})_{3}{ }^{2+}$ and a coreactant to generate an $\mathrm{ECL}$ signal. ${ }^{28} \mathrm{ECL}$ coreactants are species that, upon electrochemical oxidation or reduction, produce intermediates that react with other compounds to produce excited states capable of emitting light. ${ }^{29-31}$ For example, in the $\mathrm{Ru}(\mathrm{bpy})_{3}{ }^{2+} /$ tri- $n$-propylamine (TPrA) system, ${ }^{32,33}$ an anodic potential oxidizes $\mathrm{Ru}(\mathrm{bpy}) 3^{2+}$ to $\mathrm{Ru}(\mathrm{bpy}) 3^{3+}$. The coreactant is also oxidized and decomposes to produce a reducing agent than can interact with $\mathrm{Ru}(\mathrm{bpy}) 3^{3+}$ to form the excited state (i.e., ${ }^{*} \mathrm{Ru}(\mathrm{bpy}){ }_{3}{ }^{2+}$ ).

Therefore, the electrochemistry, spectroscopy and ECL of Ru(bpy) ${ }^{2+}$ were studied in a series of fluorinated and nonfluorinated alcohols and alcohol/water mixtures with the goal of understanding the ground- and excited-state properties in these potentially important systems.

\section{EXPERIMENTAL SECTION}

Materials. $\mathrm{Ru}(\mathrm{bpy}){ }_{3} \mathrm{Cl}_{2} \cdot 6 \mathrm{H}_{2} \mathrm{O}$ (98\%, Strem Chemical, Newburyport, MA), ethanol (200 proof, Aaper Alcohol and Chemical Co., Shelbyville, KY), 1-propanol (99.7\%, Sigma-Aldrich, St. Louis, MO), 2-propanol ( $>95 \%$, Flinn Scientific, Inc., Batavia, IL), 1-butanol (99.8\%, Sigma-Aldrich), 2,2,2-trifluoroethanol ( $\geq 99 \%$, Aldrich, St. Louis, MO), 2,2,3,3-tetrafluoro-1-propanol (98\%, Aldrich), 1,1,1,3,3,3-hexafluoro-2-propanol (>99\%, Aldrich), 2,2,3,4,4,4hexafluoro-1-butanol (95\%, Aldrich), and tri- $n$-propylamine (98\%, Aldrich) were used as supplied. Nonaqueous electrochemical and ECL experiments used tetra- $n$-butylammonium hexafluorophosphate $\left(\mathrm{Bu}_{4} \mathrm{NPF}_{6}\right.$; Aldrich) as the supporting electrolyte. Aqueous experiments (including alcohol/water mixtures) were performed in potassium phosphate (Spectrum Chemical Manufacturing Corp., Gardena, CA) buffered solution. Deionized water was filtered using a Barnstead/Thermolyne triple filtration system.

Methods. Electrochemical analysis including square wave and cyclic voltammetry without photon detection utilized a CH Instruments electrochemical analyzer (Austin, TX) with a glassy carbon working electrode (to prevent adsorption of compound on the electrode surface). The glassy carbon electrode was cleaned after each run by polishing with $0.05-\mu \mathrm{m}$ alumina, followed by rinsing with deionized and filtered water, sonication in dilute nitric acid solution, and rinsing with water a second time.

ECL instrumentation and experimental methods have been previously described ${ }^{34}$ and incorporated a conventional threeelectrode system incorporating a $\mathrm{CH}$ Instruments electrochemical analyzer and a Hamamatsu HC 135 photomultiplier tube contained in a "light-tight" box. Luminophore concentrations were between 100 and $0.1 \mathrm{nM}$ and contained $40 \mathrm{mM}$ TPrA and $0.1 \mathrm{M} \mathrm{Bu}_{4} \mathrm{NPF}_{6}$ in nonaqueous solutions or $0.18 \mathrm{M}$ potassium phosphate at $\mathrm{pH}$

(28) (a) Yang, H.; Leland, J. K.; Yost, D.; Massey, R. J. Biotechnology 1994, 12, 193. (b) Blackburn G. F.; Shah, H. P.; Kenten, J. H.; Leland, J.; Kamin, R. A.; Lonk, J.; Pterman, J.; Powell, M. J.; Shah, A.; Talley, D. B.; Tyagi, S. K.; Wilkins, E.; Wu, T. C.; Massey, R. J. Clin. Chem. 1991, 37, 1626.

(29) Chang, M. M.; Saji, T.; Bard, A. J. J. Am. Chem. Soc. 1977, 99, 5399-5403. (30) Rubinstein, I.; Bard, A. J. J. Am. Chem. Soc. 1981, 103, 512-516. (31) White, H. S.; Bard, A. J. J. Am. Chem. Soc. 1982, 104, 6891-6895. (32) Leland, J. K.; Powell, M. J. J. Electrochem. Soc. 1990, 137, 3127-3131. (33) Miao, W.; Choi, J.-P.; Bard, A. J. J. Am. Chem. Soc. 2002, 124, 14478. (34) McCall, J.; Alexander, C.; Richter, M. M. Anal. Chem. 1999, 71, 2523. 


\section{Table 1. Electrochemical and ECL Data for Ru(bpy) $3^{2+}$ in Mixed Alcohol/Water Solutions}

solvent

water

5\% 1,1,1,3,3,3-hexafluoro-2-propanol (HFP)

$30 \%$ 2,2,2-trifluoroethanol (TFE)

3\% 2,2,3,4,4,4-hexafluoro-1-butanol (HFB)

$30 \%$ 2-fluoroethanol (FE)

$30 \%$ ethanol (EtOH)

$30 \%$ 2-propanol (2-PrOH)

$30 \%$ 1-propanol (1-PrOH)

10\% 2,2,3,3-tetrafluoro-1-propanol (TFP)

$5 \%$ 1-butanol $(\mathrm{BuOH})$

$E_{1 / 2}{ }^{\mathrm{A} a}(\mathrm{~V})$
1.08
1.18
1.18
1.22
1.12
1.12
1.12
1.10
1.10
1.10

$\Delta E_{1 / 2}(\mathrm{~V})$
1.98
2.32
2.28
2.28
2.10
2.10
2.09
2.08
2.07
2.06

${ }^{a}$ Versus $\mathrm{Ag} / \mathrm{AgCl}$ reference electrode with $0.18 \mathrm{M}$ potassium phosphate, $\mathrm{pH}=8.0 \pm 0.2 .{ }^{b}$ Potential corresponding to peak ECL intensity.

$8.0 \pm 0.2$ in aqueous (and mixed) solutions. All electrochemical and ECL experiments were referenced with respect to a $\mathrm{Ag} / \mathrm{AgCl}$ electrode $\left(0.20 \mathrm{~V}\right.$ vs NHE) ${ }^{35}$ The Pt working electrode was cleaned before each run by repeated cycling $(+2.0$ to $-2.0 \mathrm{~V})$ in 6.0 M sulfuric acid followed by sonication for $30 \mathrm{~s}$ in dilute nitric acid and rinsing in deionized water.

UV-vis spectroscopy was performed using a Cary-100 UVvisible spectrophotometer (Varian Inc., Palo Alto, CA). Photoluminescence spectroscopy and ECL spectra were obtained with a Shimadzu RF-5301 spectrofluorophotometer (Shimadzu Corp.) with detection between 500 and $700 \mathrm{~nm}$. Slit widths for PL spectroscopy were $3 \mathrm{~nm}$ while ECL spectroscopy used slit widths of $20 \mathrm{~nm}$. Excitation for photoluminescence was at the lowest energy absorption wavelength maximum. Photoluminescence efficiencies ( $\phi_{\mathrm{em}}$; photons emitted per photons absorbed) were obtained relative to $\mathrm{Ru}(\mathrm{bpy})_{3}{ }^{2+}$ in water $\left(\phi_{\mathrm{em}}\left(\mathrm{H}_{2} \mathrm{O}\right)=0.042\right),{ }^{36}$ and ECL efficiencies ( $\phi_{\text {ecl }}=$ photons generated per redox event) were obtained by literature methods, ${ }^{37,38}$ using $\mathrm{Ru}(\mathrm{bpy})_{3}{ }^{2+}$ in aqueous buffered solution $\left(\phi_{\text {ecl }}=1\right)$ as the standard. Observed photoluminescence efficiencies were corrected for varying refractive indices as shown in the equation below, where $n$ is the refractive index of the solvent and $n_{\mathrm{w}}$ is the refractive index of water. ${ }^{39}$

$$
\phi_{\mathrm{r}}=\phi_{\mathrm{r}}^{\mathrm{obs}}\left(n^{2} / n_{\mathrm{w}}^{2}\right)
$$

Refractive indices of solvent systems were tested using a Bausch and Lomb refractometer with an attached water circulation system to maintain a constant temperature of $25^{\circ} \mathrm{C}$. Values of pure solvents were compared to literature values ${ }^{40}$ with less than $0.09 \%$ error.

Solvent systems were chosen based upon the proportion of alcohol to water (by volume) that resulted in highest PL and ECL emission. For highly miscible alcohols, $30 \%$ was found to be optimum. Other alcohols were mixed to their maximum miscibility in potassium phosphate-buffered aqueous solution.

(35) Bard, A. J., Faulkner, L. R. Electrochemical Methods Fundamentals and Applications, 2nd ed.; Wiley: New York, 2001.

(36) Van Houten, J.; Watts, R. J. J. Am. Chem. Soc. 1976, 98, 4853.

(37) White, H. S.; Bard, A. J. J. Am. Chem. Soc. 1977, 99, 5399.

(38) Richter, M. M.; Bard, A. J.; Kim, W. K.; Schmehl, R. H. Anal. Chem. 1998, $70,310$.

(39) Demas, J. N.; Crosby, G. A. J. Phys. Chem. 1971, 75, 991-1024.

(40) CRC Handbook of Chemistry and Physics, Lide, D. R., Ed.; Taylor and Francis: Boca Raton, FL, 2006.
Reported values for ECL intensity are based upon the average of at least three scans with a relative standard deviation of $\pm 10 \%$. Values for photoluminescence intensity and electrochemical oxidations and reductions are based upon the average of at least three scans with a relative standard deviation of $\pm 5 \%$.

\section{RESULTS AND DISCUSSION}

Electrochemical Properties. Cyclic and square wave voltammetry were used to study the effect of different solvents on the redox potentials for the oxidation and reduction of $\mathrm{Ru}(\mathrm{bpy})_{3}{ }^{2+}$. Data are presented in Table 1 for the mixed alcohol/water systems. The electrochemistry of Ru(bpy) ${ }_{3}{ }^{2+}$ has been extensively studied in protic and aprotic solvents ${ }^{2,41}$ and is known to display one metal-centered oxidation and three consecutive ligand-based reductions. Unfortunately, only one reduction was observed in these experiments due to reduction of the solvent at potentials lower than $-1.4 \mathrm{~V}$ (Table 1). All redox processes were reversible with anodic and cathodic peak currents for an electrochemical couple (i.e., $i_{\mathrm{a}} / i_{\mathrm{c}}$ ) of $\sim 1.0$ and a peak-to-peak separation $\left(\Delta E_{\mathrm{pp}}\right)$ of $\sim 70 \mathrm{mV} . \Delta E_{\mathrm{pp}}$ is less than or equal to that observed for ferrocene $^{+/ 0}$ under similar conditions indicating one-electron processes, as expected.

Interestingly, the anodic half-wave potentials $\left(E_{1 / 2}^{\mathrm{A}}\right)$ and cathodic half-wave potentials $\left(E_{1 / 2}^{\mathrm{C}}\right)$ shift in the presence of fluorinated alcohols. For example, $E_{1 / 2} \mathrm{~A}$ is $+1.177 \mathrm{~V}$ and $E_{1 / 2} \mathrm{C}$ is $-1.107 \mathrm{~V}$ for $30 \%(\mathrm{v} / \mathrm{v}) \mathrm{TFE} / \mathrm{H}_{2} \mathrm{O}$ compared to +1.076 and -0.908 $\mathrm{V}$ in water, indicating a greater splitting between the lowest unoccupied molecular orbital (LUMO) of $\mathrm{Ru}(\mathrm{bpy})_{3}{ }^{2+}$ and its highest occupied molecular orbital (HOMO) in the hydroxylic solvents as compared to water. This suggests a stronger interaction between $\mathrm{Ru}(\mathrm{bpy})_{3}{ }^{2+}$ and solvent molecules that may be due to hydrogen-bonding interactions and greater polarity in the alcohol/water mixtures. ${ }^{1,26,27}$

Cyclic voltammograms of $\mathrm{Ru}(\mathrm{bpy})_{3}{ }^{2+}$ in the presence of TPrA show a broad, irreversible oxidation centered at $\sim+0.9 \mathrm{~V}$ characteristic of TPrA. ${ }^{32}$ Also, the peak potential and current of the oxidative wave are independent of solution composition (e.g., $30 \%$ (v/v) $\mathrm{TFE} / \mathrm{H}_{2} \mathrm{O}$ vs $\mathrm{H}_{2} \mathrm{O}$ ) within experimental error.

UV-vis and Photoluminescence. Typical UV-vis absorption and photoluminescence spectra for Ru(bpy) ${ }_{3}{ }^{2+}$ in 30:70 (v/v) TFE/ $\mathrm{H}_{2} \mathrm{O}$ is shown in Figure 1. Data for $\mathrm{Ru}(\mathrm{bpy})_{3}{ }^{2+}$ in all the solvents are presented in Table 2 . UV-vis spectra of $\mathrm{Ru}(\mathrm{bpy})_{3}{ }^{2+}$ are

(41) Tokel, N.; Bard, A. J. J. Am. Chem. Soc. 1972, 94, 2862-2863.

6406 Analytical Chemistry, Vol. 79, No. 16, August 15, 2007 


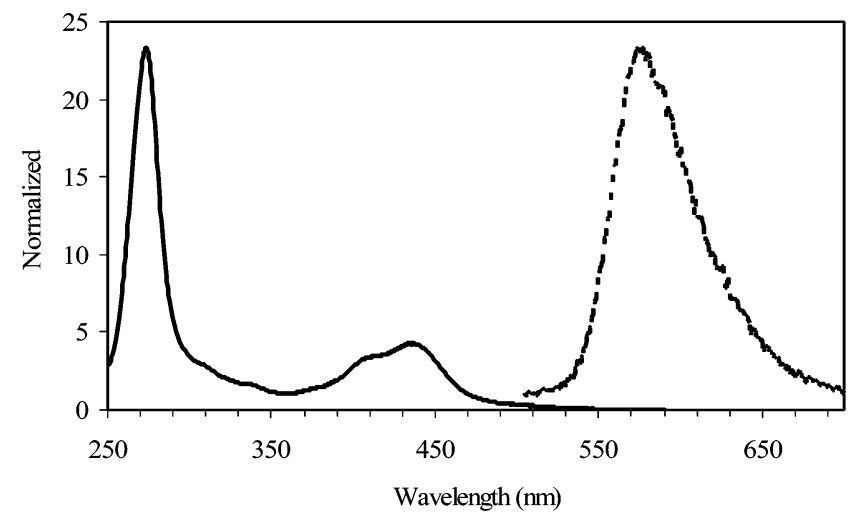

Figure 1. UV-vis (-) and photoluminescence (- -) of $10^{-5} \mathrm{M}$ $\mathrm{Ru}(\mathrm{bpy})_{3}{ }^{2+}$ in $30: 70(\mathrm{v} / \mathrm{v}) \mathrm{TFE} /$ water $(0.18 \mathrm{M}$ potassium phosphate, $\mathrm{pH}=8.0 \pm 0.2)$.

characterized by a series of ligand-based transitions in the UV with $\mathrm{Ru}(\mathrm{d} \pi)-\mathrm{bpy}\left(\pi^{*}\right)$ MLCT bands in the visible..$^{1-4}$ The energies of the MLCT bands are slightly solvent dependent, and the absorption energy for the lowest energy maximum shifts between 0 and $10 \mathrm{~nm}$ higher in energy on going from water to the alcohols and mixed alcohol/water solvents. For example, $\lambda_{\text {abs }}=453 \mathrm{~nm}$ for $\mathrm{Ru}(\mathrm{bpy}){ }_{3}{ }^{2+}$ in water and $446 \mathrm{~nm}$ in both TFE and 30:70 (v/v) TFE $/ \mathrm{H}_{2} \mathrm{O}$. This correlates with the $\Delta E_{1 / 2}\left(E_{1 / 2}{ }^{\mathrm{A}}-E_{1 / 2} \mathrm{C}\right)$ values (Table 1). Interestingly, the ligand based $\pi-\pi^{*}$ absorption centered around $286 \mathrm{~nm}$ appears less solvent dependent than the MCLT transitions. Similar results were observed for $\mathrm{Ru}(\mathrm{bpy})_{3}{ }^{2+}$ and several osmium-polypyridine complexes in aprotic solvents ${ }^{42}$ and was interpreted based on the dielectric continuum theory, where the dielectric constant of the solvent can influence electronic transition energies. ${ }^{43}$ Furthermore, the study indicated that initial population of the MLCT states was localized on a single ligand, ${ }^{42}$ allowing a dipole to exist that can interact with the solvent sphere.

Excitation into the broad visible absorbance band around 450 $\mathrm{nm}$ produces room-temperature luminescence for $\mathrm{Ru}(\mathrm{bpy}){ }_{3}{ }^{2+}$ in all solvents and mixtures. An emission band is observed at 599 $\mathrm{nm}$ in water and at higher energies in alcohol and alcohol:water mixtures (Table 2). Since it is possible to estimate solvent polarity using the refractive index ${ }^{27}$ (a higher refractive index indicates a lower solvent polarity), these values were obtained (Table 2) and used to compare emission wavelengths and photoluminescence efficiencies with solvent polarity. In general, $\lambda_{\mathrm{em}}$ increased with increasing polarity of the solvent. A study of $\mathrm{Ru}(\mathrm{bpy}){ }_{3}{ }^{2+}$ in a series of monovalent linear alcohols observed a similar trend. ${ }^{26,27}$ As expected, given the solvent-dependent nature of the UV-vis and electrochemical data, HFP displays the greatest blue shift with an emission maximum at $562 \mathrm{~nm}$. In fact, a comparison between $\Delta E_{1 / 2}$ of mixed solutions and PL emission wavelength shows a clear correlation (Figure 2). As the dipole moment of ${ }^{*} \mathrm{Ru}(\mathrm{bpy}){ }_{3}{ }^{2+}$ is more strongly influenced by solvent interactions, the HOMOLUMO gap increases resulting in larger $\Delta E_{1 / 2}$ values and higher energy emission. This matches other studies on $\mathrm{Ru}(\mathrm{bpy}){ }_{3}{ }^{2+}$ where changes in nature of the solvation sphere effected both the

(42) Kober, E. M.; Sullivan, B. P.; Meyer, T. J. Inorg. Chem. 1984, 23, 20982104.

(43) (a) Marcus, R. A. J. Chem. Phys. 1965, 43, 1261-1274. (b) Marcus, R. A. J. Chem. Phys. 1963, 39, 1734-1740. radiative and nonradiative decay processes ${ }^{1,3,4,26,27}$ In the case of hydroxylic solvents, the interactions are via hydrogen bonding and dipole forces between the electron-rich diimine region ${ }^{44}$ of $\mathrm{Ru}(\mathrm{bpy}){ }_{3}{ }^{2+}$ and the solvent molecules. ${ }^{27}$

Photoluminescence efficiencies ( $\phi_{\mathrm{em}}$; photons emitted per photons absorbed) for $\mathrm{Ru}(\mathrm{bpy})_{3}{ }^{2+}$ are reported in Table 2 and are also solvent dependent. In general, the values are lower than Ru(bpy) ${ }^{2+}$ in water. However, for the mixed solvent systems of $30 \%$ $\mathrm{EtOH}, 30 \%$ 2-PrOH, $10 \% \mathrm{TFP}$, and $5 \% \mathrm{BuOH}$, they are higher than $\phi_{\mathrm{em}}$ in water or pure alcohol under identical conditions. The photoluminescence efficiencies also tend to increase with lower solvent polarity. This was also observed for $\mathrm{Ru}(\mathrm{bpy})_{3}{ }^{2+}$ in a series of nonfluorinated alcohols as well as $\mathrm{TFE}^{27}$ and was traced to increased nonradiative decay as the polarity of the solvent increased.

Electrogenerated Chemiluminescence. ECL was observed for $\mathrm{Ru}(\mathrm{bpy}){ }_{3}{ }^{2+}$ in aqueous, alcohol, and mixed alcohol/water solutions at a Pt interface by sweeping to positive potentials in the presence of $0.04 \mathrm{M}$ TPrA. An example of ECL intensity versus [TPrA] at constant concentration of $\mathrm{Ru}(\mathrm{bpy})_{3}{ }^{2+}$ is shown in Figure 3. Maximum intensity was reached at $40 \mathrm{mM}$ TPrA in a majority of the solvent systems. Therefore, this concentration of coreactant was used for all ECL studies. It is well-known that $\mathrm{Ru}(\mathrm{bpy}){ }_{3}{ }^{2+}$ can react with hydroxyl groups to produce ECL. This occurs upon oxidation in aqueous alkaline solutions of $\mathrm{pH} \geq 10 .{ }^{45}$ To be certain that the alcohols were acting as solvents and not coreactants, all experiments in this study were run at $\mathrm{pH}=8.0 \pm 0.2$. Background studies also confirmed that very little ECL was emitted at this $\mathrm{pH}$ when TPrA was absent from solution.

The ECL intensity peaks at potentials between +1.1 and +1.3 $\mathrm{V}$ (Table 1 and Figure 4$)$, indicating oxidation of both TPrA $\left(E_{\mathrm{a}}\right.$ $\sim+0.9 \mathrm{~V}$ vs $\mathrm{Ag} / \mathrm{AgCl})^{32,33}$ and $\mathrm{Ru}(\mathrm{bpy}){ }_{3}{ }^{2+}\left(E_{1 / 2}{ }^{\mathrm{A}}\right.$ from +1.0 to $+1.2 \mathrm{~V})$ has occurred. ECL emission spectra in each solvent (Figure 5) are similar to photoluminescence spectra in both shape and wavelength of maximum emission, indicating the same MLCT excited state is formed in both experiments. Also, it indicates that the effects of the solvent sphere observed in PL experiments are similar for the ECL excited state and that the presence of TPrA and electrolytes in solution does not interfere with these processes.

ECL efficiencies ( $\phi_{\text {ecl }}$; photons emitted per redox event) are shown in Table 2. Due to the insolubility of aqueous electrolytes in pure alcohols, $\mathrm{Bu}_{4} \mathrm{NPF}_{6}$ was used to study the ECL of $\mathrm{Ru}$ (bpy) ${ }_{3}{ }^{2+}$ in these solvents. All others used $0.18 \mathrm{M}$ potassium phosphate. For the pure alcohols, $\phi_{\text {ecl }}$ mirrors the trends observed for $\phi_{\mathrm{em}}$. Namely, the lower the polarity of the solvent the higher the emission efficiency. For example, TFP has a refractive index of 1.3210 and $\phi_{\text {ecl }}$ of 0.800 while HFP has $n=1.2750$ and $\phi_{\text {ecl }}=$ 0.072 . In the mixed solvent systems, however, the picture is more complex and no clear trend between solvent polarity and emission efficiency is observed. For example, 30\% TFE has $n=1.3266$ and $\phi_{\mathrm{ecl}}=267.7$, water has $n=1.3331$ and $\phi_{\mathrm{ecl}}=1.00$, and $30 \% \mathrm{EtOH}$ has $n=1.3507$ and $\phi_{\mathrm{ecl}}=14.8$. The reasons for this are unclear

(44) Krug, W. P.; Demans, J. N. J. Am. Chem. Soc. 1979, 101, 4394.

(45) (a) Karatani, H.; Kojima, M.; Minakuchi, H.; Soga, N.; Shizuki, T. Anal. Chem. Acta 1997, 337, 207-215. (b) Karatani, H. J. Photochem. Photobiol. 1994, 79, 71-80. (c) Karatani, H.; Shizuki, T. Electrochim. Acta 1996, 41, 16671676. (d) Chen, X; Jia, L.; Wang, X.; Hu, G. Anal. Sci. 1997, 13, 71-75. (e) Chen, X.; Sato, M.; Lin, Y. Microchem. J 1998, 58, 13-20. (f) Chen, X.; Jia, L.; Sato, M. Ниахие Хиеbаo 1998, 56, 238-243. 
Table 2. Spectroscopic and ECL Data for Ru(bpy) $3^{2+}$

\begin{tabular}{|c|c|c|c|c|c|c|c|c|}
\hline solvent & $n^{a}$ & $\lambda_{\text {abs }}(\mathrm{nm})$ & $\lambda_{\mathrm{abs}}(\mathrm{nm})$ & $\lambda_{\mathrm{em}^{b}}(\mathrm{~nm})$ & $\phi_{\mathrm{em}}{ }^{\text {obs } c}$ & $\phi_{\mathrm{em}}^{\prime} d$ & $\lambda_{\mathrm{ecl}}(\mathrm{nm})$ & $\phi_{\mathrm{ecl}^{e, f}}$ \\
\hline $\mathrm{H}_{2} \mathrm{O}$ & 1.3331 & 453 & 286 & 599 & 0.042 & 0.042 & 604 & 1.0 \\
\hline HFP & 1.2750 & 443 & 282 & 562 & 0.021 & 0.019 & & $0.072^{g}$ \\
\hline $5 \%$ HFP & 1.3318 & 452 & 286 & 573 & 0.022 & 0.022 & 580 & 12.6 \\
\hline TFE & 1.2907 & 446 & 283 & 571 & 0.033 & 0.030 & & $0.094^{g}$ \\
\hline $30 \%$ TFE & 1.3266 & 446 & 284 & 578 & 0.032 & 0.031 & 588 & 267.7 \\
\hline $\mathrm{HFB}$ & 1.3128 & 444 & 285 & 566 & 0.038 & 0.036 & & $0.27^{g}$ \\
\hline $3 \% \mathrm{HFB}$ & 1.3330 & 443 & 282 & 583 & 0.020 & 0.020 & 590 & 0.54 \\
\hline 2-FE & 1.3639 & 450 & 283 & 586 & 0.036 & 0.038 & & - \\
\hline $30 \% 2$-FE & 1.3474 & 451 & 286 & 588 & 0.041 & 0.042 & 598 & 23.0 \\
\hline EtOH & 1.3603 & 451 & 287 & 588 & 0.032 & 0.033 & & - \\
\hline $30 \% \mathrm{EtOH}$ & 1.3507 & 451 & 286 & 591 & 0.050 & 0.051 & 598 & 14.8 \\
\hline 2-PrOH & 1.3763 & 449 & 287 & 591 & 0.033 & 0.035 & & - \\
\hline $30 \% 2-\mathrm{PrOH}$ & 1.3553 & 453 & 286 & 593 & 0.052 & 0.053 & 600 & 46.4 \\
\hline 1-PrOH & 1.3841 & 451 & 287 & 590 & 0.027 & 0.029 & & - \\
\hline $30 \% 1-\mathrm{PrOH}$ & 1.3550 & 453 & 286 & 594 & 0.039 & 0.041 & 600 & 73.2 \\
\hline TFP & 1.3210 & 445 & 284 & 574 & 0.040 & 0.039 & & $0.80^{g}$ \\
\hline $10 \%$ TFP & 1.3341 & 450 & 285 & 594 & 0.046 & 0.046 & 600 & 68.8 \\
\hline $\mathrm{BuOH}$ & 1.3983 & 453 & 288 & 593 & 0.031 & 0.034 & & - \\
\hline $5 \% \mathrm{BuOH}$ & 1.3375 & 453 & 286 & 596 & 0.048 & 0.049 & 603 & 6.42 \\
\hline
\end{tabular}

${ }^{a}$ Refractive index of solvent without Ru(bpy) $3^{2+}$ or electrolyte. ${ }^{b}$ Excited at respective lowest energy absorption $(443-453 \mathrm{~nm}) .{ }^{c} \varphi \mathrm{em}$ calculated with respect to $\varphi_{\text {ref }}=0.042$ for $\mathrm{Ru}(\mathrm{bpy}){ }_{3}{ }^{2+}$ in $\mathrm{H}_{2} \mathrm{O} .{ }^{d}$ Corrected for refractive index (see eq 1$) \cdot{ }^{e} \varphi_{\text {ecl }}$ calculated with respect to $\varphi_{\text {ref }}=1.00$ for $\mathrm{Ru}$ (bpy) $3_{3}{ }^{+}$in aqueous buffered solution containing $0.18 \mathrm{M}$ potassium phosphate, $\mathrm{pH}=8.0 \pm 0.2$. Solutions contained $100 \mathrm{nM}$ Ru(bpy) $3^{2+}$ with 40 mM TPrA. ${ }^{f}$ Average ECL intensities were $\sim 80000$ count $/ \mathrm{s}$ for $10^{-8} \mathrm{M} \mathrm{Ru}(\mathrm{bpy})_{3}{ }^{2+}$ in the absence of alcohol. ${ }^{g} 0.1 \mathrm{M} \mathrm{TBAPF}_{6}$ as electrolyte.

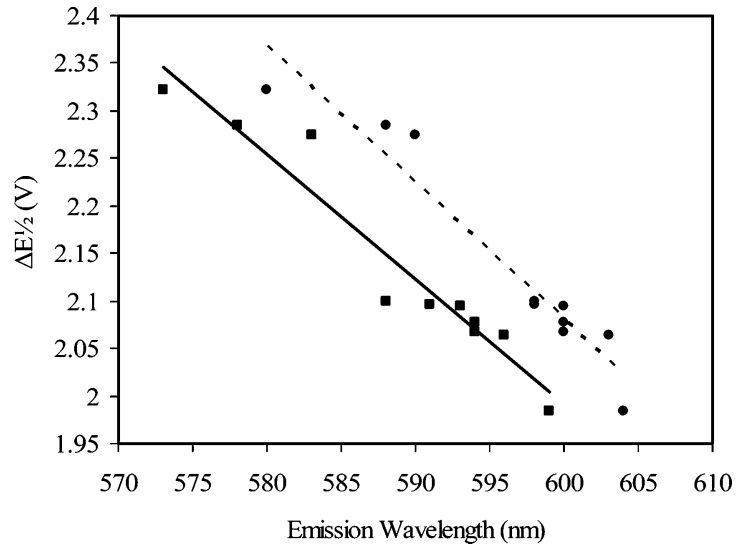

Figure 2. $\Delta E_{1 / 2}$ vs $\mathrm{PL}$ emission wavelength $(\mathbf{\square},-)$ and $\mathrm{ECL}$ emission wavelength $(\mathbf{O},--)$. PL: $R^{2}=0.9333, y=-0.0131 x+$ 9.867. ECL: $R^{2}=0.9273, y=-0.0144 x+10.702$.

but may reflect hydrogen-bonding interactions between the alcohols and water, with size and shape of the alcohol influencing the extent to which the solvent sphere interacts with the excitedstate complex.

Surprisingly, the alcohol/water mixtures show dramatic increases in $\phi_{\mathrm{ecl}}$ compared to the reference $\mathrm{Ru}(\mathrm{bpy}){ }_{3}{ }^{2+} / \mathrm{H}_{2} \mathrm{O}$ system $\left(\phi_{\mathrm{ecl}}=1.0\right)$. For example, $5 \% \mathrm{BuOH}$ has a $\phi_{\mathrm{ecl}}$ value of 6.4 while $30 \% \mathrm{EtOH}$ has a value of 14.78 and $30 \% \mathrm{TFE}$ a value of 267.7. These increases are comparable to and in some cases much larger than increases observed for the ECL of $\mathrm{Ru}(\mathrm{bpy}){ }_{3}{ }^{2+} / \mathrm{TPrA}$ in surfactant solution. ${ }^{46-48}$ In the case of the nonionic surfactant Triton X-100 (polyoxyethylene(10) isooctylphenyl ether), it was shown that adsorption of surfactant on Pt and Au electrodes renders the surface more hydrophobic, ${ }^{46}$ facilitating coreactant oxidation and leading to 10-fold increased $\mathrm{ECL}$ intensities in the $\mathrm{Ru}(\mathrm{bpy})_{3}{ }^{2+}$ /

(46) Zu, Y.; Bard, A. J. Anal. Chem. 2001, 73, 3960.

(47) Workman, S.; Richter, M. M. Anal. Chem. 2000, 72, 5556.

(48) Factor, B.; Muegge, B.; Workman, S.; Bolton, E.; Bos, J.; Richter, M. M. Anal. Chem. 2001, 73, 4621.

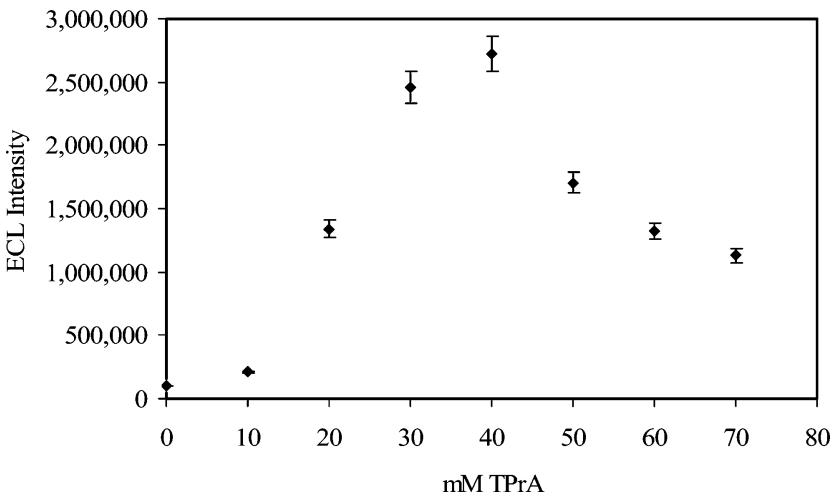

Figure 3. $E C L$ intensity vs [TPrA]. $10 \mathrm{nM} \mathrm{Ru(bpy)})_{3}{ }^{2+}$ in 30:70 TFE/ water $(0.18 \mathrm{M}$ potassium phosphate, $\mathrm{pH}=8.0 \pm 0.2)$. Each point is the average of three runs with error bars at $\pm 10 \%$.

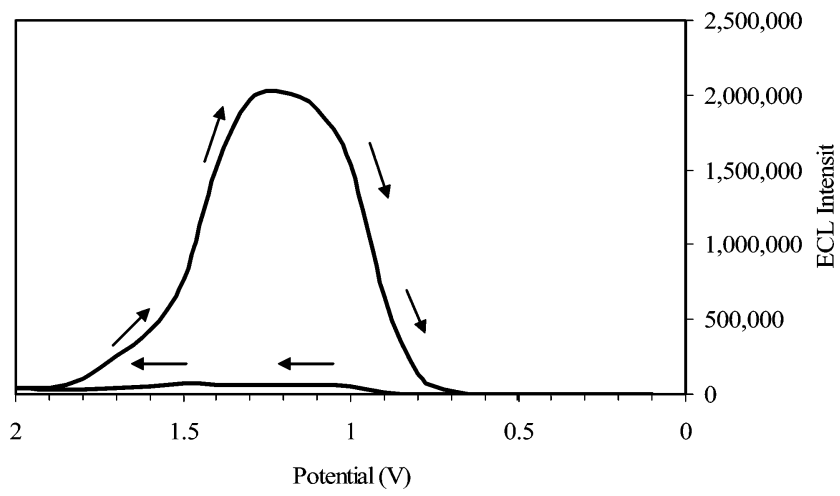

Figure 4. $E C L$ intensity vs potential for $10 \mathrm{nM} \mathrm{Ru(bpy)})_{3}{ }^{2+}$ in 30:70 $(\mathrm{v} / \mathrm{v}) \mathrm{TFE} /$ water $(0.18 \mathrm{M}$ potassium phosphate, $\mathrm{pH}=8.0)$. Arrows indicate the direction of forward and reverse scans.

TPrA system. This work was extended to a nonionic fluorosurfactant $(\sim 50 \text {-fold enhancement })^{49}$ and to ionic surfactants $(\sim 30$ fold enhancement) ${ }^{50}$ Another approach to enhancing ECL emission

(49) Li, F.; Zu, Y. Anal. Chem. 2004, 76, 1768-1772.

(50) Xu, G.; Pang, G.; Xu, B.; Dong, S.; Wong, K.-Y. Analyst 2005, 130, 541.

6408 Analytical Chemistry, Vol. 79, No. 16, August 15, 2007 


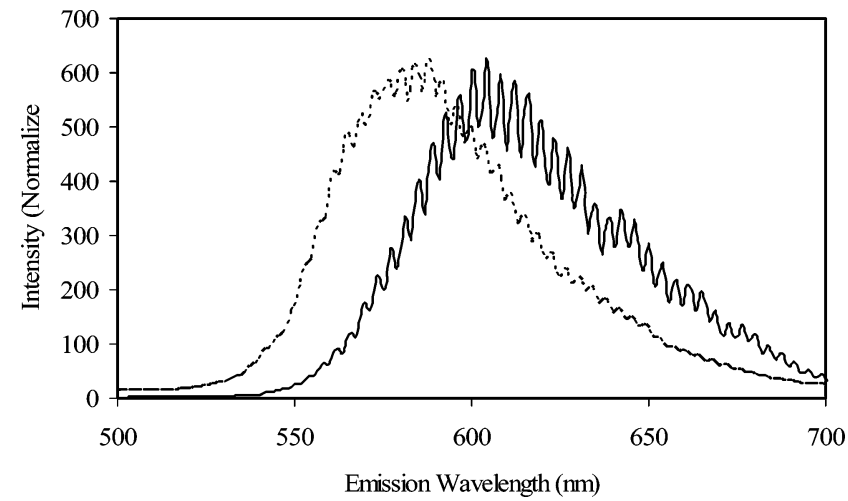

Figure 5. Normalized ECL spectra of $10^{-5} \mathrm{M} \mathrm{Ru}(\mathrm{bpy})_{3}{ }^{2+}(0.18 \mathrm{M}$ potassium phosphate, $\mathrm{pH}=8.0 \pm 0.2)$ in aqueous solution $(-)$ and $30 \%$ TFE (- - ).

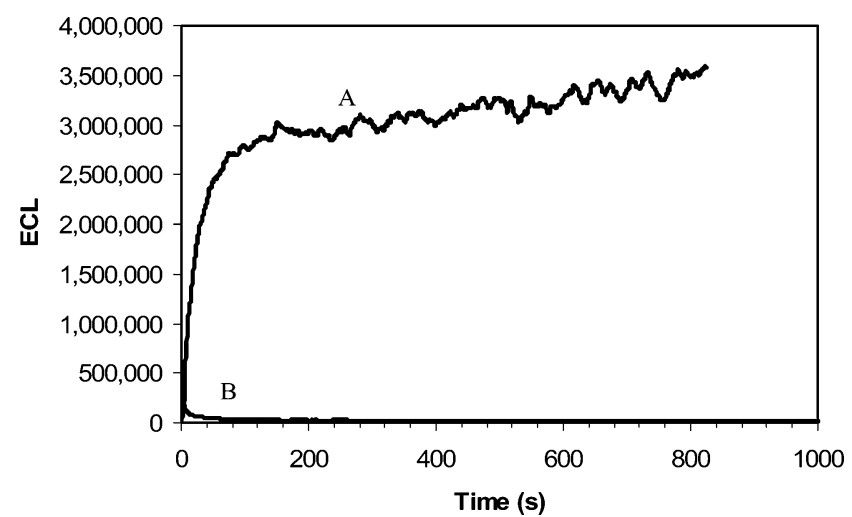

Figure 6. $E C L$ intensity vs time for $100 \mathrm{nM} \mathrm{Ru}(\mathrm{bpy})_{3}{ }^{2+}$ in (A) 30:70 TFE $/ \mathrm{H}_{2} \mathrm{O}(\mathrm{v} / \mathrm{v})$ and $(\mathrm{B})$ 0:100 TFE $/ \mathrm{H}_{2} \mathrm{O}(\mathrm{v} / \mathrm{v})$ with $40 \mathrm{mM}$ TPrA and $0.18 \mathrm{M}$ potassium phosphate $\mathrm{pH}=8.0$. The potential was poised at $+2.0 \mathrm{~V}$ for the duration of the experiment.

has been to find more efficient luminophores. For example, in aqueous solution, Os(phen $)_{2}(\text { dppene })^{2+}($ dppene $=$ bis (diphenylphosphino)ethene) ${ }^{51}$ shows a 2 -fold increase in $\phi_{\text {ecl }}$ compared to $\mathrm{Ru}(\mathrm{bpy})_{3}{ }^{2+}$, which was increased more than 10 -fold upon addition of Triton X-100.52 By varying the ligands attached to the metal center in orthometalated iridium(III), systems resulted in 77 times higher ECL from iridium(III) complexes in the presence of TPrA than that of the Ru(bpy) $3_{3}{ }^{2+} / \mathrm{TprA}$ system. ${ }^{53} \mathrm{~A} 2-3$-fold enhancement was also observed for the bimetallic ruthenium system $\left[(\mathrm{bpy})_{2} \mathrm{Ru}\right]_{2}(\mathrm{bphb})^{4+}\left(\mathrm{bphb}=1,4-\mathrm{bis}\left(4^{\prime}\right.\right.$-methyl-2,2'-bipyridin-4-yl)benzene) using both annihilation and coreactant meth$\mathrm{ods}^{38}$ and up to 5 -fold for a dendrimeric systems containing eight $\mathrm{Ru}(\mathrm{bpy})_{3}{ }^{2+}$ units at the periphery ${ }^{54}$ of a carbosilane dendrimer platform. Clearly, the use of mixed alcohol/water mixtures, most notably 30:70 (v/v) TFE/ $\mathrm{H}_{2} \mathrm{O}$, leads to significant improvement in ECL and potentially much lower detection limits compared to $\mathrm{Ru}(\mathrm{bpy})_{3}{ }^{2+} / \mathrm{TPrA}$ in water, surfactant solutions, and alternate ECL luminophores. The effect of surfactants on the ECL emission of

(51) Bruce, D.; Richter, M. M.; Brewer, K. J. Anal. Chem. 2002, 74, 3157.

(52) Walworth, J.; Brewer, K. J.; Richter, M. M. Anal. Chim. Acta. 2004, 503 (2), 241.

(53) Kim, J. I.; Shin, I.-S.; Kim, H.; Lee, J.-K. J. Am. Chem. Soc. 2005, 127, 1614-1615.

(54) Zhou, M.; Roovers, J. Macromolecules 2001, 34, 244.
$\mathrm{Ru}(\mathrm{bpy}) 3^{2+} / \mathrm{TPrA}$ in both fluorinated and nonfluorinated alcohols is currently under study.

ECL is linear with respect to $\left[\mathrm{Ru}(\mathrm{bpy})_{3}{ }^{2+}\right]$ in all mixed solvent systems with concentration of $\mathrm{Ru}(\mathrm{bpy})_{3}{ }^{2+}$ being varied from from 100 to $0.1 \mathrm{nM}$. Correlation coefficients $\left(r^{2}\right)$ ranged from 0.9806 to 0.9988 (a minimum of 4 data points with a standard deviation of $\pm 5 \%)$. A table with full equations and $r^{2}$ values can be found in the Supporting Information.

A typical ECL intensity versus time transient for $\mathrm{Ru}(\mathrm{bpy})_{3}{ }^{2+}$ in a mixed solvent (i.e., 30\% TFE) and in purely aqueous solution is shown in Figure 6. The potential of the working electrode was poised at $+2.0 \mathrm{~V}$ over the course of $800 \mathrm{~s}$ while measuring ECL intensity. As expected, in the absence of TFE, there was an immediate increase in light intensity due to the higher concentrations of coreactant and luminophore near the electrode surface that then decreased over time and repeated cycling. This behavior has been observed for $\mathrm{Ru}(\mathrm{bpy}){ }_{3}{ }^{2+}$ in other solvent systems and indicates that ECL generation is diffusion controlled. Interestingly, when $30 \% \mathrm{TFE}$ is present in solution, the ECL continues to rise over the course of the experiment. This reasons for this are unclear but suggests that more ECL reaction events are occurring in the presence of the fluorinated solvent, which may also explain the enhanced ECL intensities.

\section{CONCLUSIONS}

This study illustrates the effects of a series of hydroxylic solvents, including fluorinated alcohols, on the electrochemical, spectroscopic, and coreactant (TPrA) electrogenerated chemiluminescence of $\mathrm{Ru}(\mathrm{bpy}){ }_{3}{ }^{2+}$. Hydrogen bonding and dipole forces lead to dramatic changes in the ground- and excited-state properties in $\mathrm{Ru}(\mathrm{bpy}){ }_{3}{ }^{2+}$, including a larger difference between the first electrochemical reduction and oxidation $\left(\Delta E_{1 / 2}\right)$ and shifts in UVvis absorption, PL, and ECL bands. Most notably, the higher the polarity of the solvent, the larger $\Delta E_{1 / 2}$ and the higher energy of maximum PL and ECL emission. Effects are also seen in PL and ECL quantum yields for emission, where in all but the mixed solvent ECL reactions, increases in $\phi_{\mathrm{em}}$ and $\phi_{\mathrm{ecl}}$ are, in general, related to lower polarity solvents. Dramatic increases in $\phi_{\mathrm{ecl}}$ ranging from 6-to 270-fold are observed in mixed solvent systems compared to $\mathrm{Ru}(\mathrm{bpy}){ }_{3}{ }^{2+} / \mathrm{TPrA}$ in water and open up a new area for fundamental and applied ECL studies. For example, fluorinated solvents may prove useful in diagnostic or environmental applications where greater sensitivity and detection limits are required.

\section{ACKNOWLEDGMENT}

The authors thank the Camille and Henry Dreyfus Foundation for support of this work in the form of a Henry Dreyfus TeacherScholar award (M.M.R.).

\section{SUPPORTING INFORMATION AVAILABLE}

Table with full regression equations and $r^{2}$ values. This material is available free of charge via the Internet at http://pubs.acs.org.

Received for review May 20, 2007. Accepted May 25, 2007.

AC071028X 